\title{
Phase transformation during mechano-synthesis of nanocrystalline/amorphous Fe-32Mn-6Si alloys
}

\author{
Rasool Amini ${ }^{a, *}$, Ali Shamsipoor ${ }^{a}$, Mohammad Ghaffari ${ }^{b}$, \\ Morteza Alizadeh ${ }^{a}$, Ali Kemal Okyay ${ }^{b}$ \\ ${ }^{a}$ Department of Materials Science and Engineering, Shiraz University of Technology, 71555-313 Shiraz, Iran \\ ${ }^{b}$ Department of Electrical and Electronics Engineering, UNAM-National Institute of Materials Science and Nanotechnology Bilkent University, \\ Ankara 06800, Turkey
}

\section{A R T I C L E D A T A}

\section{Article history:}

Received 2 September 2012

Received in revised form 19 July 2013

Accepted 22 July 2013

\section{Keywords:}

Fe-Mn-Si shape memory alloys

Mechanical alloying

Phase transformation

Nanostructural/amorphous phase

Microstructure

\begin{abstract}
A B S T R A C T
Mechano-synthesis of Fe-32Mn-6Si alloy by mechanical alloying of the elemental powder mixtures was evaluated by running the ball milling process under an inert argon gas atmosphere. In order to characterize the as-milled powders, powder sampling was performed at predetermined intervals from 0.5 to $192 \mathrm{~h}$. X-ray florescence analyzer, X-ray diffraction, scanning electron microscope, and high resolution transmission electron microscope were utilized to investigate the chemical composition, structural evolution, morphological changes, and microstructure of the as-milled powders, respectively. According to the results, the nanocrystalline Fe-Mn-Si alloys were completely synthesized after $48 \mathrm{~h}$ of milling. Moreover, the formation of a considerable amount of amorphous phase during the milling process was indicated by quantitative X-ray diffraction analysis as well as high resolution transmission electron microscopy image and its selected area diffraction pattern. It was found that the $\alpha$-to- $\gamma$ and subsequently the amorphous-to-crystalline (especially martensite) phase transformation occurred by milling development.
\end{abstract}

(c) 2013 Elsevier Inc. All rights reserved.

\section{Introduction}

Fe-Mn-Si alloys are a class of smart materials due to their suitable shape memory effect (SME), excellent machinability and formability, low cost, good weldability and corrosion resistance, and high strength having several industrial applications such as dampers, pipe couplings, big shape memory devices, hard metals or alloys joining, oxygen blowing nozzles and so on [1-11].

The production of stress induced martensite $(\varepsilon, \mathrm{hcp})$ from parent austenite phase $(\gamma, \mathrm{fcc})$ and the reverse transformation $(\gamma$ to $\varepsilon$ ) during the heating cycle are the origins of SME in this alloying system [12-18]. This non-thermoelastic or semi-thermoelastic conversion occurred by the creation of stacking faults (SFs) due to the movement of the Shockley partial dislocations $\left(a_{\gamma} / 6<112>\right)$ in the parent phase. SFs are suitable sites for nucleation of the martensite phase; eventually, the $\varepsilon$-phase can be formed by their overlap [12,17-23].

Although induction melting under an argon gas atmosphere is widely utilized to produce Fe-based SMAs, solid-state routes such as mechanical alloying (MA) can be used to produce the alloys in the powder form [24]. During MA, by applying the high energy collision between ball and particles and consequently the repeated cold welding and fracture of the powders, not only is the alloying process attained but also the synthesis of the non-equilibrium structures such as supersaturated solid solutions, nanocrystalline and amorphous structures, and intermetallic compounds is possible [24-28].

Recently, MA has been widely used to synthesize nanocrystalline and amorphous SMAs [29-31], although limited investigations have been done on Fe-Mn-Si alloys. To the best

\footnotetext{
* Corresponding author. Tel.: +98 711 7354500; fax: +98 7117354520 .

E-mail addresses: ramini2002@gmail.com, amini@sutech.ac.ir (R. Amini).
} 
of our knowledge, the only work was done by Saito et al. [24] in which the alloy system was fabricated by MA and its structure was evaluated qualitatively. In the present work, the alloying system with the nominal composition of Fe-32Mn-6Si was produced by MA and an attempt was made to study the structural and microstructural phase evaluation of the alloyed powders quantitatively.

\section{Materials and Methods}

Fe-32Mn-6Si shape memory alloys were synthesized by mechanical alloying (MA) of high purity elemental Fe $\left(>99.5 \%, \quad D_{\mathrm{v}}=50 \mu \mathrm{m}\right), \quad \mathrm{Mn} \quad\left(>99.8 \%, \quad D_{\mathrm{v}}=50 \mu \mathrm{m}\right)$, and $\mathrm{Si}$ $\left(>99.8 \%, D_{\mathrm{v}}=10 \mu \mathrm{m}\right)$ powders under an inert argon gas atmosphere. MA was performed in a planetary ball mill (Sepahan $84 \mathrm{D}$ ) with a tempered steel vial (capacity $=90 \mathrm{ml}$ ) and balls $(4 \times 20 \mathrm{~mm}$ and $8 \times 10 \mathrm{~mm})$ under dry conditions up to $192 \mathrm{~h}$. A rotation speed of $400 \mathrm{rpm}$ and the ball-to-powder mass ratio of 20:1 were used for this purpose.

The chemical composition of the as-milled powders was determined by an X-ray fluorescence analyzer (XRF, PHILIPS, PW2400) in which the quantitative values were extracted by the PAN analytical software. The morphological change of the powder particles was evaluated by a scanning electron microscope (SEM, FEI, Nova Nanosem 430). Also, the phase constituent and structural properties of the powders were studied by using the powder X-ray diffraction (XRD, Pananalytical, X'pert Pro MPD, $C u K \alpha_{1,2}$ radiations) method. The data were collected at room temperature in the $2 \theta$ range of $30^{\circ}$ to $100^{\circ}$ in the step size of $0.03^{\circ}$, with an integration time of $6 \mathrm{sec} / \mathrm{step}$. The X-ray tube was operated at $40 \mathrm{kV}$ and $40 \mathrm{~mA}$. The present phases were identified using the Match software after filtering the $\mathrm{CuK} \alpha_{2}$ radiation component. The quantitative phase analysis of the XRD results was performed by Rietveld refinement using the MAUD software package version 2.3. The average crystallite size and the lattice strain were determined by the Double-Voigt approach and the quantity of the amorphous phase was estimated from the overestimation of an internal crystalline standard in the Rietveld refinement of an appropriate mixture of a standard and the sample powders [32-35]. In the present work, fully crystalline Mo powder with a median crystallite size of $50 \mathrm{~nm}$ was used as an internal standard. It should be noticed that, in the Rietveld analysis, to minimize the difference between the experimental and calculated patterns, parameters such as zero point error, sample displacement, scale factor, unit cell parameter, temperature factor, microabsorption, crystallite size, and lattice strain were refined for each phase.

Finally, in order to investigate the microstructure of as-milled powders as well as to confirm the XRD results, the powders

Table 1 - The chemical composition of the $192 \mathrm{~h}$ milled powders.

\begin{tabular}{lllllll}
\multicolumn{8}{c}{ Weight percent (\%) } \\
\hline Milling time & Fe & \multicolumn{1}{c}{ Mn } & Si \\
& Con & AE & Con & AE & Con & AE \\
192 & 62.48 & 0.05 & 31.78 & 0.03 & 5.74 & 0.02 \\
\hline \multicolumn{7}{l}{ Con, concentration; AE, absolute error. } \\
\hline
\end{tabular}

dropped down in copper grid after dispersed in ethanol, and then were characterized by a high-resolution transmission electron microscope (HRTEM, FEI, Tecnai G2 F30).

\section{Results and Discussion}

\subsection{Chemical Composition Assessment}

In the milling process, because of possible impurities coming from the milling media to the as-milled powders and consequently a deviation from the compound stoichiometry, the chemical composition measurements are very essential. Table 1 shows the chemical composition of the alloyed powder after considerably long milling times (192 h). As it can be seen, the expected nominal composition of Fe-32Mn-6Si was achieved and the amount of impurities from the milling media is negligible.

\subsection{Qualitative Phase Analysis}

The XRD profiles of the as-milled powders at different milling times including 6, 12, 24, 48, 96 and $192 \mathrm{~h}$ are presented in Fig. 1. Concerning the XRD patterns of the powders at early stages of milling, the dissolution of $\mathrm{Mn}$ and Si occurred in the $\alpha$-Fe phase and by increasing the milling process, a decrease in the crystallite size and an increase in the lattice strain occurred [24], which resulted in the peaks broadening. By progression of milling, owing to the formation of different structural defects such as dislocations and vacancies during the MA process, the free energy level of the $\alpha$-phase can be increased and consequently the probability of its transformation to the more stable phases increases. In addition, due to severe plastic deformation, the long-range order in the structure can be broken down to short-range order or possibly disordered structure and subsequently the amorphization process occurred [36]. This is verified by the halo in the XRD patterns of the $48 \mathrm{~h}$ milled powders. At sufficiently high milling times (e.g. $96 \mathrm{~h}$ or $192 \mathrm{~h}$ ), due to the formation and overlapping of the stacking faults in the parent phase, stress induced martensite can be formed. Moreover, the mechanical crystallization of the amorphous phase to the more stable crystalline phases occurred at the moment. One important reason of mechano-crystallization of the amorphous phase is the powder's temperature rising during the milling process. It should be mentioned that the temperature distribution during milling is more complicated than a simple overall temperature in the vial and a crucial disparity exists between the temperature of the milling balls and vials [37]. During milling, one part of the milled powders is attached to the balls, other part is attached to the vial walls, and the remaining part is in a free state moving in the volume of the vial. All the parts have different temperatures wherein the part attached to the balls can be experience significantly high temperatures (in the order of several hundreds of ${ }^{\circ} \mathrm{C}$ ) depends on the milling conditions [37].This can be the reason that the crystalline phases creates from the amorphous phase during MA. On the other hand, it is recognized that, due to the severe collision between the milling media and the milled powders, local (microscopic) temperature rising can be considerably high, 


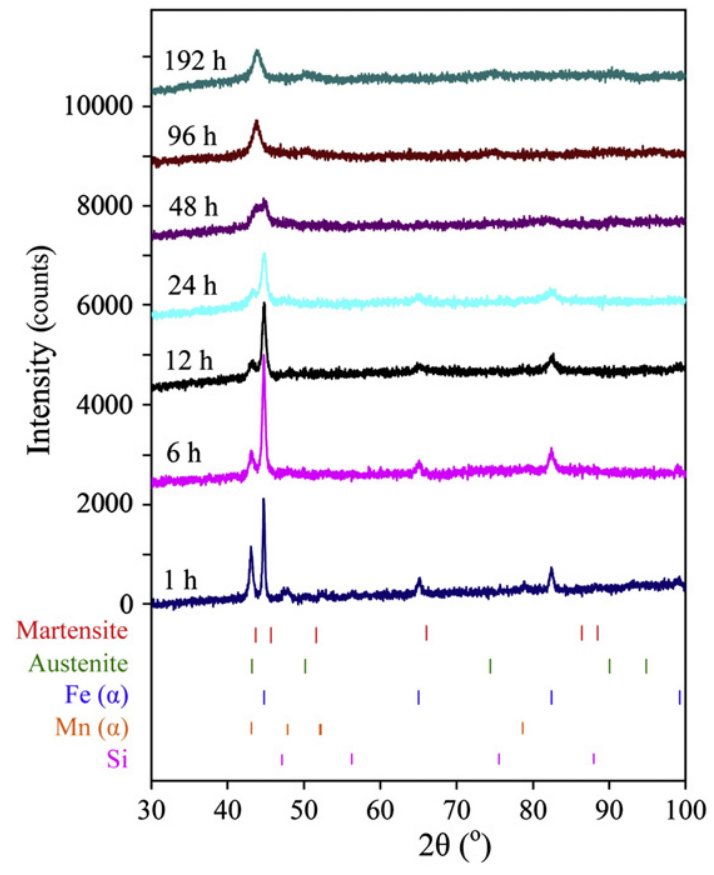

Fig. 1 - XRD profiles of the as-milled powders at different milling times.

often more than the melting points of some alloying systems $[25,36,38]$. Since the crystallization temperature of the present alloying system is around $500{ }^{\circ} \mathrm{C}$ (concerning the thermal analysis results done on the as-milled powders which is not reported in the present paper), it can be inferred that the mechano-crystallization of the amorphous phase during milling is due to the increase of the powders temperature to a value well-above the crystallization temperature of the amorphous phase.

\subsection{Quantitative Phase Analyses}

As mentioned in Materials and methods, the quantity of crystalline phases was estimated by the Rietveld refinement of the XRD results. Moreover, the fraction of the amorphous phase was determined from the overestimation of a fully crystalline Mo powder (as an internal standard) in the Rietveld refinement of an appropriate mixture of Mo and the milled powders (here: 75 wt.\% milled powders and 25 wt.\% Mo) using the following equation [32].

$A=\frac{1-\left(W_{\mathrm{S}} / R_{\mathrm{S}}\right)}{100-W_{\mathrm{S}}} \times 10^{4} \%$

where $W_{S}(\%)$ is the weight concentration of the internal standard (in this study $W_{S}=25 \%$ ) and $R_{S}(\%)$ is its Rietveld analyzed concentration. To achieve the reliable results and to estimate the potential errors, the XRD data collections and the quantitative Rietveld analyses were repeated thrice in three specimens.

Fig. 2 shows the quantity variations of the amorphous and crystalline phases by milling development. As it can be seen, the amorphization process was started even at short milling times and after $6 \mathrm{~h}$ of milling the structure of the powders contains about 33\% amorphous phase and 67\% crystalline phase (consists of $47.4 \% \alpha$-bcc, $0.6 \% \mathrm{Si}, 19 \% \alpha-\mathrm{Mn}$ ). By milling evolution, the amount of crystalline phases decreases where $\mathrm{Si}$ and $\mathrm{Mn}$ are completely dissolved in the structure after 12 and $48 \mathrm{~h}$ of milling, respectively. Furthermore, due to dissolution of total $\mathrm{Mn}$ and $\mathrm{Si}$ as well as formation of a high density of defects in the parent $\alpha$-phase, the $\alpha$-to- $\gamma$ phase transformation is evident after $48 \mathrm{~h}$ of milling. The enhancement of the amorphous phase also continues until $48 \mathrm{~h}$ of milling in which its maximum amount is reached (84 wt.\%). By milling development to $96 \mathrm{~h}$ and $192 \mathrm{~h}$, mechano-crystallization of the amorphous phase occurred, which is attributed to the temperature rising during the MA process. Moreover, the formation of stress induced martensite is determined by quantification of the XRD results of the powders milled for $96 \mathrm{~h}$ and $192 \mathrm{~h}$. It can be attributed to the formation of stacking faults and also the stresses introduced due to severe plastic deformation during the milling cycle.

The variations of crystallite size and lattice strain of the different crystalline phases by milling time are demonstrated in Fig. 3 (a) and (b), respectively. As it is obvious, the crystallite size of the initial phases as well as the $\gamma$ and $\varepsilon$ phases, created during the milling process, was reduced considerably by milling progression. Furthermore, it can be seen that as a result of severe collisions between balls and the powder particles, the crystalline defects and consequently the lattice strains increase considerably by milling evolution.

\subsection{SEM Observation}

The microstructural and morphological evaluations of the powders at various milling times are investigated by SEM analysis (Fig. 4). Since the alloying system is ductile-ductile, the cold welding process prevailed over fracture at early stages of milling (e.g. $0.5 \mathrm{~h}$ ) and the plate-like morphology with the average particle size of $17 \mu \mathrm{m}$ is developed (Fig. 4 (a)). By progression of milling, due to domination of cold welding, the agglomerated particles are created (Fig. 4 (b)) and the average particle size increases considerably, reaching $38 \mu \mathrm{m}$ after 24 h of milling (Fig. 4 (c)). By development of milling, due to the amorphous phase increasing, the brittleness of the powders increases and the average particle size is reduced significantly $(12 \mu \mathrm{m})$. At this stage, due to occurrence of a balance between cold welding and fracturing, the particles morphology tends to be semi-spherical (Fig. 4 (d)). At the final stages of milling (e.g. 96 h), owing to mechano-crystallization

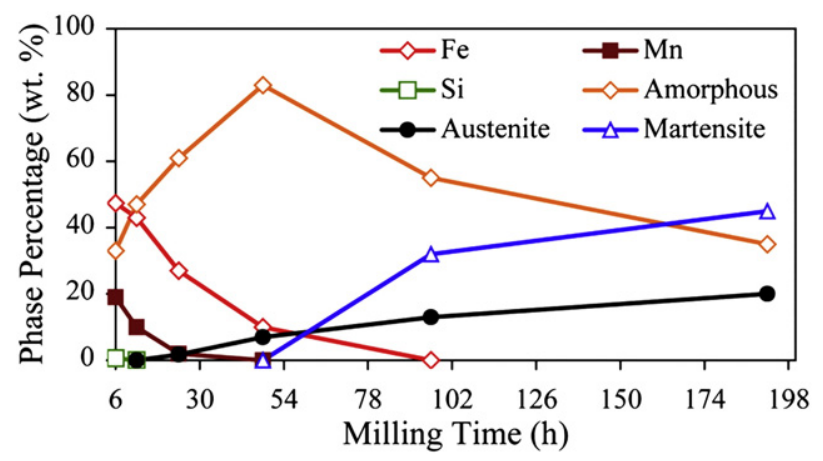

Fig. 2 - The quantity variations of different phases as a function of milling time. 

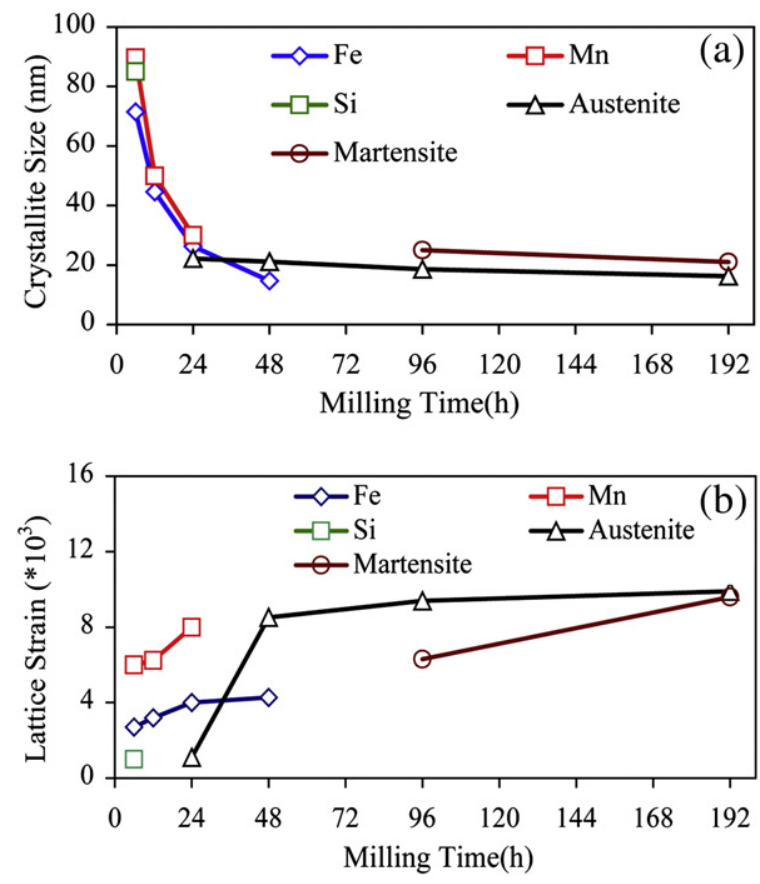

Fig. 3 - The variations of (a) crystallite size and (b) lattice strain of the different crystalline phases by milling time.

of the amorphous phase, the ductility of powders is enhanced; consequently, the cold welding process overcomes the fracture mechanisms, resulting in the irregular particles with the average size of $27 \mu \mathrm{m}$ (Fig. 4 (e), (f)).

\subsection{TEM Observation}

The high resolution TEM images and the corresponding selected area diffraction patterns of the $48 \mathrm{~h}$ and $96 \mathrm{~h}$ milled powders are shown in Fig. 5 (a) and (b), respectively. Concerning the HRTEM images, the structure of the powders contains a combination of crystalline and amorphous phases which is compatible with the crystalline rings and the amorphous halo pattern of the correlated SAD pattern. Since in the $48 \mathrm{~h}$ milled sample the fraction of the amorphous phase was significantly higher than the $96 \mathrm{~h}$ milled sample, the HRTEM image of the $48 \mathrm{~h}$ milled sample is more featureless and its correlated SAD pattern is more halo.

The origin of reflection rings of the SAD pattern of $96 \mathrm{~h}$ milled powders indicates in Fig. 6 . Based on the results, the most diffracted planes are related to martensite phase; however, the existence of the austenite phase in the structure is also evident with reference to its reflection planes (e.g. (111) and (311)). The aforementioned results are compatible with the XRD results confirming the quantitative phase analysis done by the XRD software.

\section{Conclusions}

In the present work phase transformation during mechanical alloying of Fe-32Mn-6Si alloys was evaluated. The results can be summarized as follows:

1) By starting the milling process, the average particle size was increased from $17 \mu \mathrm{m}$ to $38 \mu \mathrm{m}$, nanocrystallization
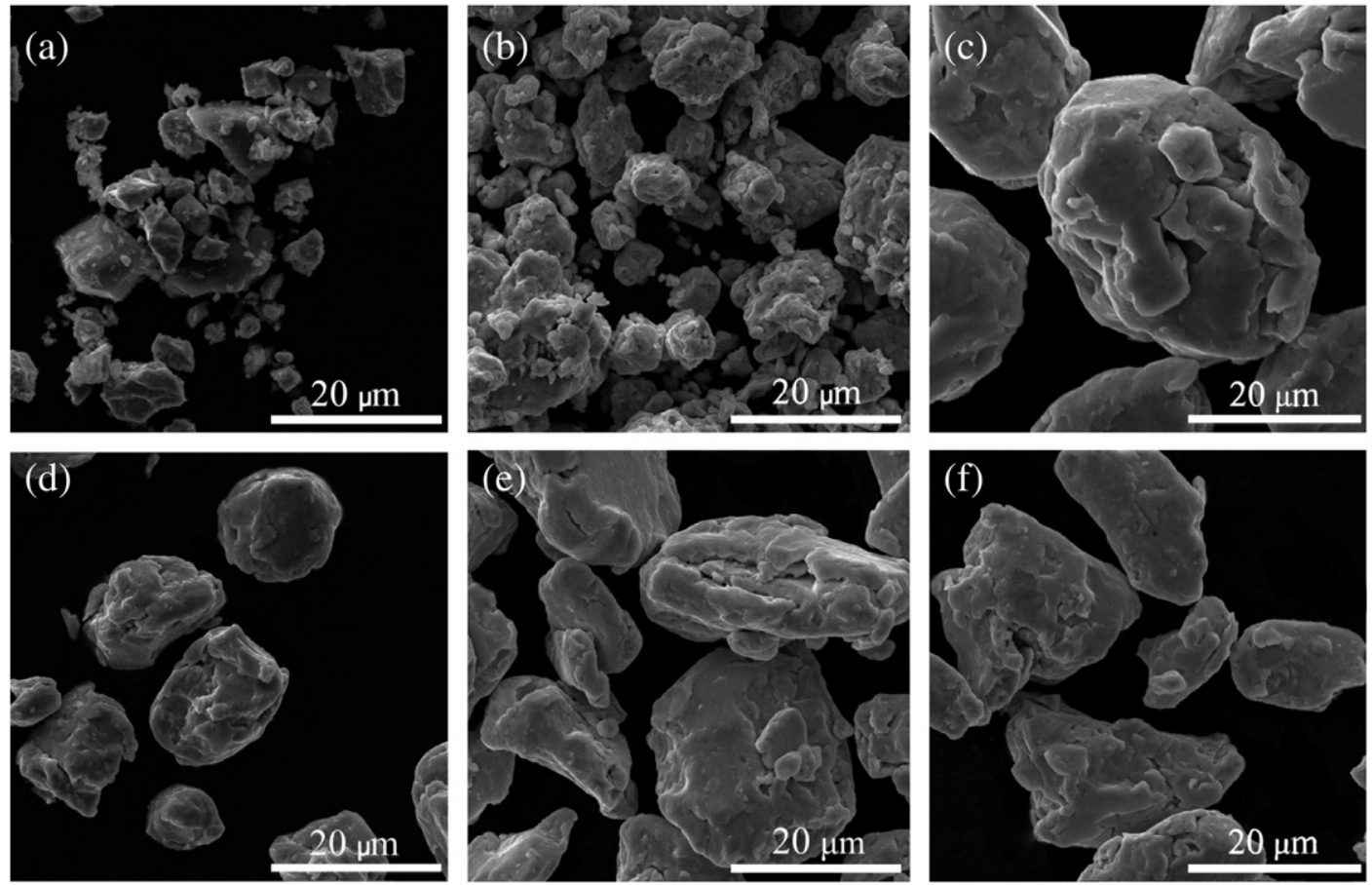

Fig. 4 - The microstructural and morphological evaluation of the alloyed powders at various milling times: (a) $0.5 \mathrm{~h}$; (b)12 h; (c) 24 h; (d) 48 h; (e) 96 h; (f)192 h. 

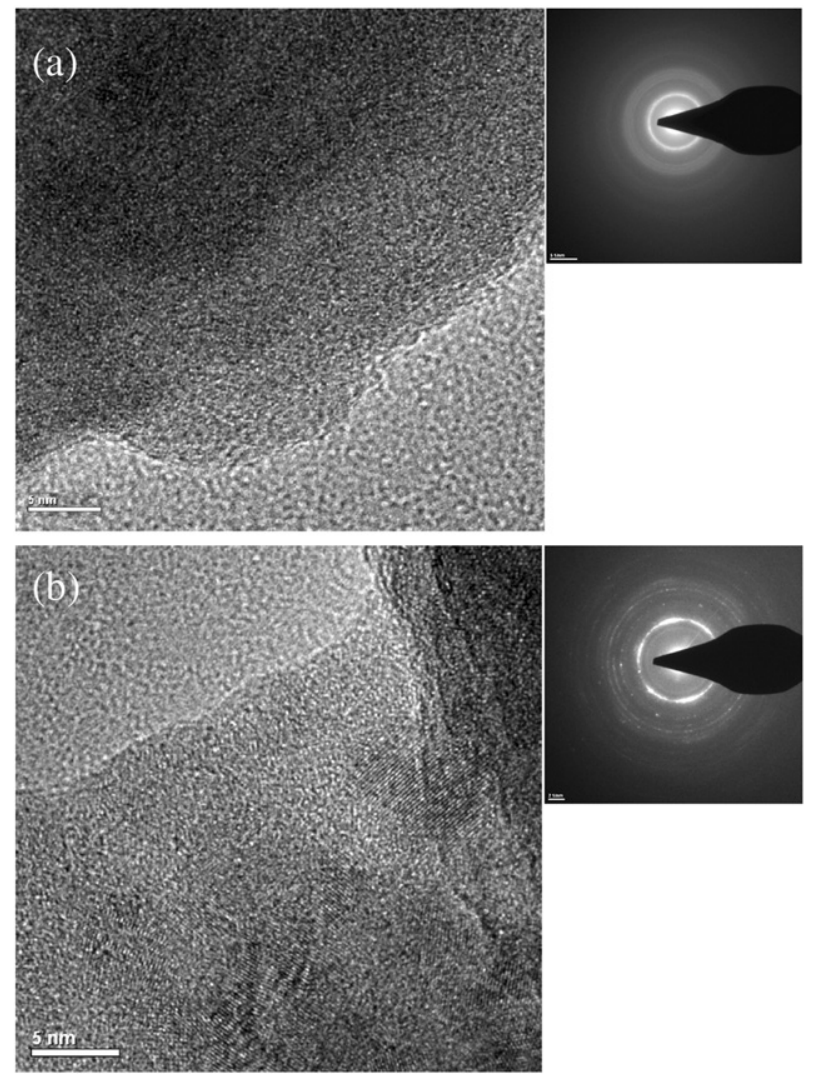

Fig. 5 - The HRTEM image and the corresponding selected area diffraction pattern of $48 \mathrm{~h} \mathrm{(a)}$ and $96 \mathrm{~h}$ (b) milled powders.

occurred and a considerable amount of amorphous phase was also created.

2) By milling progression, the $\alpha$-to- $\gamma$ phase transformation occurred the amorphous phase quantity was significantly increased reaching its maximum amount after $48 \mathrm{~h}$ of milling (84 wt.\%). At the time interval, the average particles size was reduced from $38 \mu \mathrm{m}$ to $12 \mu \mathrm{m}$ and their morphology was changed from plate like to semi-spherical.

3) After sufficient milling time (e.g. $96 \mathrm{~h}$ and $192 \mathrm{~h}$ ), the mechano-crystallization of the amorphous phase happened and its amount was reduced from $84 \mathrm{wt} . \%$ to $39 \mathrm{wt} . \%$ by milling development. Furthermore, a considerable amount (up to $47 \mathrm{wt} . \%$ ) of the $\varepsilon$-martensite phase was created. At the moment, the powders morphology was changed from semi-spherical to irregular shapes and their size was increased again (from $12 \mu \mathrm{m}$ to $27 \mu \mathrm{m}$ ).

\section{R E F E R E N C E S}

[1] Kubo H, Otsuka H, Farjami S, Maruyama T. Characteristics of Fe-Mn-Si-Cr shape memory alloys in centrifugal casting. Scr Mater 2006;55:1059-62.

[2] Sato A, Kubo H, Maruyama T. Mechanical properties of FeMn-Si based SMA and the application. Mater Trans 2006;47: 571-9.

[3] Pricop B, Söyler U, Comaneci RI, Özkal B, Bujoreanu LG. Mechanical cycling effects at Fe-Mn-Si-Cr-Ni SMAs obtained by powder metallurgy. Phys Procedia 2010;10:125-31.

[4] Ogawa K, Sawaguchi T, Kikuchi T, Kajiwara S. Mechanism of the improvement of shape memory effects in NbC containing Fe-Mn-Si-based shape memory alloys. Mater Trans 2007;48: 869-77.

[5] Wan J, Chen S. Martensitic transformation and shape memory effect in Fe-Mn-Si based alloys. Curr Opin Solid State Mater Sci 2005;9:303-12.

[6] Wang L, Rong LJ, Yan DS, Jiang ZM, Li YY. DSC study of the reverse martensitic transformation behavior in a shape memory alloy pipe-joint. Intermetallics 2005;13: 403-7.

[7] Sekar M, Sahu PCh, Shekar NVCh, Yousuf M, Rajan KG. Electrical resistance behaviour of Fe-24 wt.\% Mn alloy under high pressure. Mater Res Bull 2002;37:1233-8.

[8] Sawaguchi T, Bujoreanu L, Kikuchi T, Ogawa K, Koyama M, Murakami M. Mechanism of reversible transformation-induced plasticity of Fe-Mn-Si shape memory alloys. Scr Mater 2008;59:826-9.

[9] Zhao C. Relationships between original microstructure and shape memory effect in an Fe-14Mn-5Si-9Cr-5Ni alloy. Mater Res Bull 1998;33:1433-8.

[10] Otsuka K, Ren X. Recent developments in the research of shape memory alloys. Intermetallics 1999;7:511-28.

[11] Ying Ch, Hai-chang J, Li-jian R, Li X, Xin-qing Zh. Mechanical behavior in NiTiNb shape memory alloys with low $\mathrm{Nb}$ content. Intermetallics 2011;19:217-20.

[12] Mostafa K, Baerdemaeker J, Van Caenegem N, Segers D, Houbaert Y. Influence of carbon on the microstructure of a Fe-Mn-Si-Cr-Ni alloy. JMEPEG 2009;18:575-81.

[13] Stanford N, Dunne DP. Effect of Si on the reversibility of stress-induced martensite in Fe-Mn-Si shape memory alloys. Acta Mater 2010;58:6752-62.

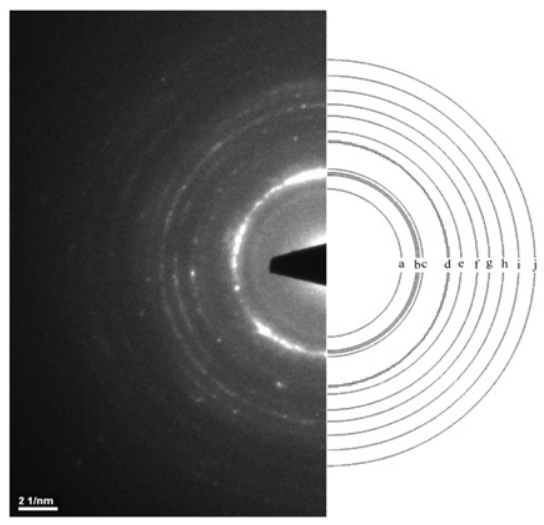

\begin{tabular}{|c|c|c|c|}
\hline circle & d.spacing(nm) & (hkl) & phase \\
\hline $\bar{a}$ & 0.232 & 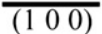 & $\bar{\varepsilon}$ \\
\hline $\mathrm{b}$ & 0.216 & $\left(\begin{array}{lll}0 & 0 & 2\end{array}\right)$ & $\varepsilon$ \\
\hline $\mathrm{b}$ & 0.207 & $\left(\begin{array}{lll}1 & 1 & 1\end{array}\right)$ & $\gamma$ \\
\hline $\mathrm{c}$ & 0.204 & $\left(\begin{array}{lll}1 & 0 & 1\end{array}\right)$ & $\varepsilon$ \\
\hline $\mathrm{d}$ & 0.1739 & $\left(\begin{array}{lll}2 & 0 & 0\end{array}\right)$ & $\gamma$ \\
\hline $\mathrm{e}$ & 0.1515 & $\left(\begin{array}{lll}1 & 0 & 2\end{array}\right)$ & $\varepsilon$ \\
\hline f & 0.1351 & $\left(\begin{array}{lll}1 & 1 & 0\end{array}\right)$ & $\varepsilon$ \\
\hline $\mathrm{g}$ & 0.1225 & $\left(\begin{array}{lll}1 & 0 & 3\end{array}\right)$ & $\varepsilon$ \\
\hline $\mathrm{h}$ & 0.1136 & $\left(\begin{array}{lll}1 & 1 & 2\end{array}\right)$ & $\varepsilon$ \\
\hline $\mathrm{i}$ & 0.1075 & $\left(\begin{array}{lll}3 & 1 & 1\end{array}\right)$ & $\gamma$ \\
\hline $\mathrm{j}$ & 0.098 & $\left(\begin{array}{lll}1 & 0 & 4\end{array}\right)$ & $\varepsilon$ \\
\hline
\end{tabular}

Fig. 6 - The origin of reflection rings of the SAD pattern of the HRTEM image of Fig. 5 (b). 
[14] Wen YH, Yan M, Li N. Effects of carbon addition and aging on the shape memory effect of Fe-Mn-Si-Cr-Ni alloys. Scr Mater 2004;50:441-4.

[15] Stanford N, Dunne DP, Monaghan BJ. Austenite stability in Fe-Mn-Si-based shape memory alloys. J Alloys Compd 2007;430:107-15.

[16] Stanford N, Dunne DP. Effect of nitrogen on damping, mechanical and corrosive properties of Fe-Mn alloys. Mater Sci Eng A 2007;454-455:407-15.

[17] Kınnd T, San U, Dikici M. The effects of pre-strain, recovery temperature, and bending deformation on shape memory effect in an Fe-Mn-Si-Cr-Ni alloy. J Alloys Compd 2009;475:145-50.

[18] Li JC, Zheng W, Jiang Q. Stacking fault energy of iron-base shape memory alloys. Mater Lett 1999;38:275-7.

[19] Bergeon N, Kajiwara S, Kikuchi T. Atomic force microscopic study of stress induced martensite formation and its reverse transformation in a thermo mechanically treated Fe-Mn-SiCr-Ni alloy. Acta Mater 2000;48:4053-64.

[20] Bergeon N, Guenin G, Esnouf C. Microstructural analysis of the stress-induced $\varepsilon$-martensite in a $\mathrm{Fe}-\mathrm{Mn}-\mathrm{Si}-\mathrm{Cr}-\mathrm{Ni}$ shape memory alloy. Mater Sci Eng A 1998;242:77-86.

[21] Kajiwara S. Characteristic features of shape memory effect and related transformation behavior in Fe-based alloys. Mater Sci Eng A 1999;273:67-88.

[22] Dai QX, Cheng XN, Zhao YT, Luo XM, Yuan ZZ. Design of martensite transformation temperature by calculation for austenitic steels. Mater Charact 2004;52:349-54.

[23] Akhondzadeh A, Zangeneh-Madar K, Abbasi SM. Influence of annealing temperature on the shape memory effect of Fe$14 \mathrm{Mn}-5 \mathrm{Si}-9 \mathrm{Cr}-5 \mathrm{Ni}$ alloy after training treatment. Mater Sci Eng A 2008;489:267-72.

[24] Saito T, Gąska K, Takasaki A, Kapusta C. Fabrication of Fe$\mathrm{Mn}-\mathrm{Si}$ alloys by mechanical alloying and direct current sintering. J Mekanikal 2010;30:62-7.

[25] Suryanarayana C. Mechanical alloying and milling. Prog Mater Sci 2001;46:1-184.

[26] Liu X, Liu Y, Ran X, An J, Cao Z. Fabrication of the supersaturated solid solution of carbon in copper by mechanical alloying. Mater Charact 2007;58:504-8.
[27] Salahinejad E, Amini R, Hadianfard MJ. Structural evolution during mechanical alloying of stainless steels under nitrogen. Powder Technol 2012;215-216:247-53.

[28] Hadef F, Otmani A, Djekoun A, Grenèche JM. Structural and microstructural study of nanostructured Fe50Al40Ni10 powders produced by mechanical alloying. Mater Charact 2011;62:751-9.

[29] Maziarz W, Dutkiewicz J, Van Humbeeck J, Czeppe T. Mechanically alloyed and hot pressed Ni-49.7Ti alloy showing martensitic transformation. Mater Sci Eng A 2004;375-377:844-8.

[30] Forouzanmehr N, Karimzadeh F, Enayati MH. Study on solid-state reactions of nanocrystalline TiAl synthesized by mechanical alloying. J Alloys Compd 2009:93-7.

[31] Mousavi T, Abbasi MH, Karimzadeh F. Synthesis and characterization of nanocrystalline NiTi intermetallic by mechanical alloying. Mater Lett 2009;63:786-8.

[32] De La Torre AG, Bruque S, Aranda MAG. Rietveld quantitative amorphous content analysis. J Appl Crystallogr 2001;34: 196-202.

[33] Kemethmuller S, Roosen A, Goetz-Neunhoeffer F, Neubauer J. Quantitative analysis of crystalline and amorphous phases in glass-ceramic composites like LTCC by the Rietveld method. J Am Ceram Soc 2006;89:2632-7.

[34] Gualtieri ML, Prudenziati M, Gualtieri AF. Quantitative determination of the amorphous phase in plasma sprayed alumina coatings using the Rietveld method. Surf Coat Technol 2006;201:2984-9.

[35] Whitfield PS, Mitchell LD. Quantitative Rietveld analysis of the amorphous content in cement and clinkers. J Mater Sci 2003;38:4415-21.

[36] Suryanarayana C. Mechanical alloying and milling. New York: Marcel Dekker; 2004 .

[37] Kwon YS, Gerasimov KB, Yoon SK. Ball temperatures during mechanical alloying in planetary mills. J Alloys Compd 2002;346:276-81.

[38] Liu DY, Sun WS, Wang AM, Zhang HF, Hu ZQ. Preparation, thermal stability, and magnetic properties of Fe-Co-Zr-MoW-B bulk metallic glass. J Alloys Compd 2004;370:249-53. 